\title{
OBSERVATIONS ON THREE SPECIES OF PHIDIPPUS JUMPING SPIDERS (ARANEAE: SALTICIDAE)*
}

\author{
By Beatrice T. Gardner \\ Department of Psychology, University of Nevada
}

The large, brightly colored jumping spiders of the genus Phidippus are among the most conspicuous American spiders. In many ways, they are ideal subjects for behavioral studies: the spiders are diurnal in habit and are highly responsive to visual stimuli, they pursue prey actively and the males perform elaborate courtship displays.

The present paper compares the behavior and the taxonomy of three Phidippus species that are found in the same fields in the vicinity of Reno, Nevada. The behavioral description emphasizes Phidippus coccineus, as this species is being used in the laboratory for experiments which continue a previous line of investigation on hunting responses (Gardner, 1964). The other two species of Phidippus, P. apacheanus and $P$. opifex, were collected and maintained in the laboratory for comparative observations.

The diagnostic features for the three species have been illustrated (Figs. I-IO) since there are few records other than the original description of each species. A modern taxonomic revision of the genus would be of considerable value in helping research workers determine specimens and in stimulating comparative studies.

Habitat

Phidippus coccineus Peckham and Peckham, 1909, occurs in the sagebrush community of the Great Basin desert. These large jumping spiders are found on bushes such as the sagebrush (Artemesia tridentata), the rabbitbrush (Chrysothamnus nauseous), and the fourwinged saltbrush (Atriplex canescens). Phidippus coccineus prefers bushes that grow on slopes with thin, stony soils, and appears to avoid conifers and moist habitats (e.g., the proximity of irrigation ditches). In the same habitat, often on the same bush, two other Phidippus species are found: P. apacheanus Chamberlin and Gertsch, 1929, and P. opifex (McCook, I883).

\section{Description}

The total size of adult $P$. coccineus ranges from 7-I I mm (median $=9 \mathrm{~mm}$ ) for males and from 10- $12 \mathrm{~mm}$ (median $=10.5 \mathrm{~mm}$ ) for females. Both males and females have blue-green irridescent cheli-

*Manuscript received by the editor February 3, 1965 


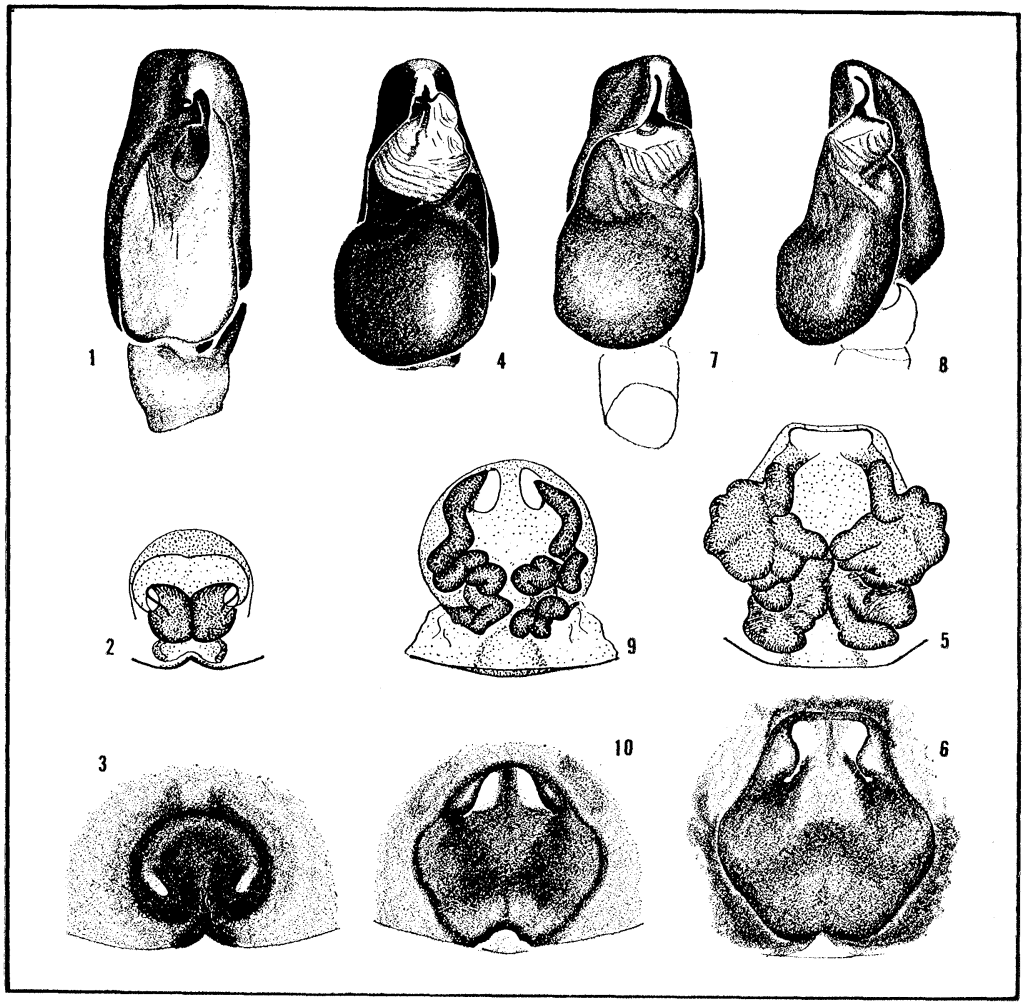

Figs. 1-3. Phidippus opifex (McCook). 1. left palpus. 2. Female genitalia, dorsal view. 3. Epigynum.

Figs. 4-6. P. apacheanus Chamberlin and Gertsch. 4. left palpus. 5. Female genitalia, dorsal view. 6. Epigynum.

Figs. 7-10. P. coccineus Peckham and Peckham. 7, 8. Left palpus. 7. Ventral view. 8. Ectal view. 9. Female genitalia, dorsal view. 10. Epigynum.

cerae, a black cephalothorax and black limbs, and a bright red abdomen with a median black stripe. There are two pairs of minute white spots between the black and red areas on the posterior part of the dorsum of the abdomen. At the sides of the abdomen there are light diagonal bands, and there is also a light transverse anterior band on the dorsum. These markings vary in conspicuousness: the bands and spots may be only a somewhat lighter shade of red than the remainder of the abdomen, while the median black stripe may be so reduced in width and length that the abdomen appears solid red. Sometimes, the basic color is orange rather than red, and very old spiders may even be yellow. In this species, the adult males and the adult females are 
similar in coloration, and this is also true of $P$. apacheanus. It is more usual for the males of Phidippus to have irridescent chelicerae and a distinctive adult coloration while the females of this genus remain similar to the immature spiders (e.g., $P$. clarus Keyserling, $P$. opifex, $P$. whitmanii Peckham and Peckham).

From the second instar on, Phidippus coccineus spiderlings have a brownish-gray cephalothorax and limbs, and a red abdomen with markings limited to the posterior portion. These consist of a pair of black stripes, each bearing two conspicuous white dots, separated by a light region. The light region may be gray, white, or even golden; immediately anterior to the black stripes it is enlarged into a conspicuous light dot. While the abdomen of very young spiderlings appear bronze, the red color of the abdomen is striking in later instars. In one of the later instars, the 5 th or perhaps the 6 th, a red cap appears in the eye region, but this marking disappears in the following molt. The light basal band and side bands of the adult are also present in immature spiders, and, in the two instars preceeding maturity, the chelicerae are also irridescent.

\section{Methods of collection}

Phidippus coccineus can be collected by sweeping bushes with an insect net. These hunting spiders are active from mid-morning until dusk, and can be seen in bushes running along branches or poised near their tips. Running is interrupted frequently: the spider stops, turns to one side and then the other, apparently scanning its surroundings. In the laboratory, the spiders are active between Io A. M. and 4 P. M., and are still in a closely-woven retreat at other times.

Adults and large immatures are found on heavier branches near the center of the brush, and are not accessible to the sweeping net. Certain characteristic aspects of their escape behavior can be used in capturing them. When approached slowly by a forefinger or a pencil, the spider backs away while facing the oncoming object, and will back right into a collecting tube held behind it on the branch. However, once the spider backs sufficiently far from the object (about $8 \mathrm{~cm}$ ), it turns away. Then it will run a short distance along the branch, attach a thread of silk, and plunge down toward the leafy debris at the base of the bush, where it becomes extremely difficult to find.

Phidippus coccineus can also be collected in its retreat, or nest. The spiders will be found within a slightly flattened tube of silk, which is surrounded by guy-lines that attach it to the twigs or leaves of the bush. The molting nest and the nest that houses the female and her cocoon of eggs are of the same basic shape as the sleeping nest, but much more silk is used in their construction. Such prominent white 
webs are found under stones at the base of the bush. Usually, the spider places its nest under one of the few stones that remains shaded from the strong desert sun even at mid-day. Occasionally, P. coccineus builds nests inside or under cardboard containers dumped in their habitat. Phidippus opifex makes frequent use of the insulation provided by these cardboard boxes; alternatively, and unlike coccineus, opifex builds a large and prominent nest among the branches of a bush to souse its egg cocoon.

\section{LIFE HISTORY}

The breeding season of $P$. coccineus appears to be a very early one. In 1964, six adult males, nine adult females, and about 90 immature spiders of this species were collected near Reno, Nevada. The males were found first, even before the final snowstorms of early June; adult males were found from early April to early July, adult females, from early May to mid-July. All but one of the females collected in May were already gravid and laid eggs within the following fortnight; all females obtained later in the summer (mainly, in July), were found in a nest with an egg cocoon. Two spiders in the penultimate instar were found in late May, and these became mature in the laboratory toward the end of June. But from mid-July on, only immature spiders could be found and none of these attained maturity during the summer or fall of 1964 , though they have molted as many as four times since coming to the laboratory. It is of some interest to note that the females survived the males by almost two months when kept under identical conditions in the laboratory, and that, for each sex, all the adults died within a short span of time (e.g., all the females between 18 Sept. 1964 and 6 Oct. 1964).

The early breeding season of $P$. coccineus contrasts with that of $P$. opifex and P. apacheanus found in the same habitat. Adult males, adult unmated females, and females in the penultimate instar of $P$. opifex were collected in the first half of July; the nests containing the egg cocoons of this species were abundant in the sagebrush late in August. Phidippus apacheanus had the latest breeding season among the three species: while immature spiders of this species were abundant throughout the spring and summer, adults were only found after the third week of September. Six immature P. apacheanus kept in the laboratory since early July molted three times and became. mature around the end of October (see Table I).

The seven $P$. coccineus females kept in the laboratory during the summer of 1964 laid either two or three successive batches of eggs, each batch containing fewer eggs. A median of 44 spiderlings hatched from the first batch of eggs, 30 from the second, and three from the single third batch that did hatch. By contrast with females that 
Table I

The 1964 breeding season for the three species of Phidippus at Reno, Nevada

\begin{tabular}{|c|c|c|c|}
\hline Collection dates for:* & $P$. coccineus & P. opifex & P. apacheanus \\
\hline $\begin{array}{l}\text { juveniles in pen- } \\
\text { ultimate instar }\end{array}$ & Oct. - June & ? - July & (Aug.) - Oct. \\
\hline adult males & April - July & July - Aug. & Sept. - Oct. \\
\hline $\begin{array}{l}\text { adult females: } \\
\text { unmated } \\
\text { gravid } \\
\text { w. egg coccoon }\end{array}$ & $\begin{array}{c}\text { May } \\
\text { May - July } \\
\text { July }\end{array}$ & $\begin{array}{c}\text { July } \\
? \\
\text { Aug. - Sept. }\end{array}$ & $\begin{array}{c}\text { Oct. } \\
\text { Oct., Nov. - ? } \\
\text { (Dec. - Jan.) *** }\end{array}$ \\
\hline
\end{tabular}

*Parentheses indicate that field collection dates are unavailable and dates for spiders maintained in the laboratory have been used.

**Possibly, abnormally early. In the laboratory, warmth and abundance of prey during the winter produces anomalies, e.g., penultimate $P$. coccineus juveniles become mature in Dec. - Jan.

bear only one batch of eggs, such as P. clarus Keyserling of the northeastern United States, coccineus females came out of their nests to capture the prey that were offered daily. Phidippus clarus remains with the egg cocoon continually, and generally dies within a few days of the spiderlings' emergence from the nest. For $P$. coccineus, the median time from oviposition to hatching was $2 \mathrm{I}$ days. The young remained in the web through a first molt some 16 days later, and emerged from the nest $2 \mathrm{I}$ days after hatching. These times show little variation: for I I batches of spiderlings the range of time from egg-laying to emergence from the nest was $37-46$ days.

The spiderlings were self-sufficient when they left the nest. If moved to an individual glass vial, almost all spiderlings built a miniature of the adult sleeping nest within two days. Flightless Drosophila placed in the vial are soon captured: for one batch of 24 spiderlings, the median catching time was $3.7 \mathrm{~min}$. and all but two of these spiderlings had caught their first prey within $60 \mathrm{~min}$. However, it is not easy to rear the spiderlings: only 30 of almost i 80 young, kept in individual vials over wet cotton wicks and fed every two days, have survived to date (i.e., approximately five months and four postemergence molts). Most of the losses occurred in the first fortnight after leaving the nest; later deaths generally occurred while the spider was molting.

\section{Courtship}

\section{Method of observation}

Complete mating behavior can be observed by placing the male together with a female reared in the laboratory from the penultimate instar to maturity, that is, a female known not to have mated pre- 
viously. In such cases, courtship is likely to be very brief: the female will accept the male after $30-60$ sec. of courtship. The initial phase of mating behavior, the courtship dance, can be observed with a wider variety of partners: females laden with eggs, females that have laid eggs, females of a different Phidippus species, females in glass vials, and even simple models of females such as hemispheres of modelling clay with a pair of wires as appendages (Drees, 1952). When a previously mated female is used, courtship is not likely to last long and may end violently: the female will run away from the male or jump at him as she does at prey. Prolonged courtship can be seen with females confined in transparent vials, and with models of the female.

A glass or plastic hemisphere $15-20 \mathrm{~cm}$ in diameter provides a suitably-sized observation chamber in which the spiders are always in full view. The chamber should have a rough textured floor as adult $P$. coccineus refuse to move or move unnaturally on a slippery surface. It is possible to use the spider's preference for moving upward to introduce animals into the chamber with a minimum of disturbance: the spider climbs into a vial placed over it in the home jar, and climbs into the chamber when the open end of the vial is fitted into a hole in its floor. As the spider is likely to orient toward the observer when he is moving, it is advisable to shield writing movements and to observe from a constant position, with a light intensity differential to further obscure the observer. The Dazor Floating Magnifier unit, which combines a wide-angle lens and fluorescent light, is very suitable for this purpose.

Results

The courtship display of various Phidippus males (apacheanus, clarus, coccineus, opifex) has a common basic pattern. The male begins his display by holding the carapace very high, shifting the abdomen to one side, and raising the first pair of legs. In this position, he moves before the female, stopping after each few steps. The male advances in a zig-zag pathway, shifting his abdomen to the other side at the end of each oblique approach. Throughout, the dancing male flicks his forelegs up and down, holding them wide apart at first and bringing them closer and closer together as he nears the female. Then, with forelegs held almost parallel before him, he touches the female cautiously once or twice. If the female remains still at this

\section{Explanation of Plate 8}

Figs. 11-12. Phidippus opifex (McCook), female, total length $14 \mathrm{~mm}$. The female is tan, the male is black with light gray dorsum of carapace and abdomen. (The white rings in the eyes are reflections of the light used.) 

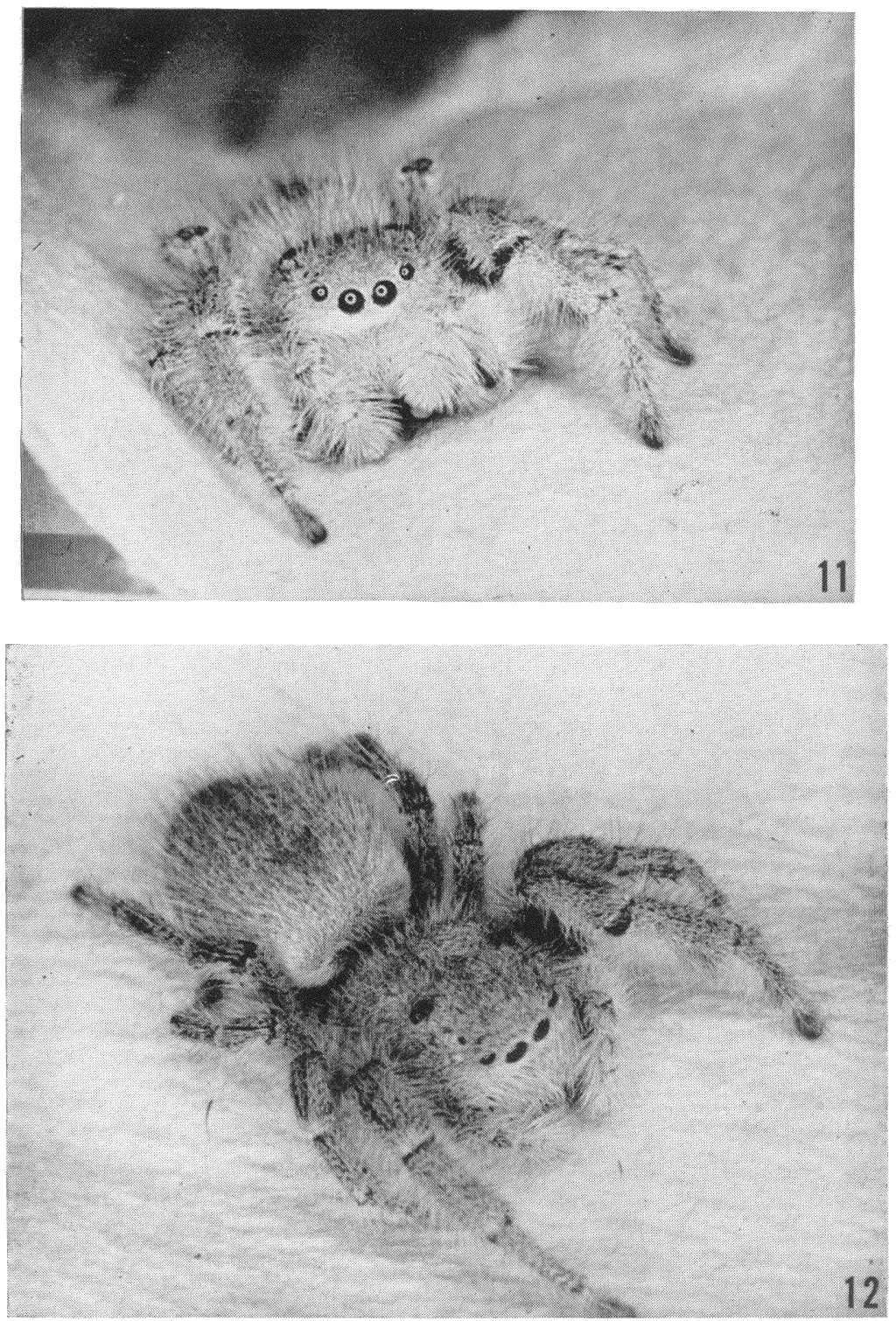

Gardner - Phidippus 
stage, the male climbs over her, and uses the forelegs to help turn her abdomen to the side. When the genital pore, which lies on the ventral abdomen, is thus exposed, the male inserts his palpus. After 2-3 min., the male withdraws this pedipalp, turns the female's abdomen in the other direction, and inserts the other pedipalp (fig. 20IO, Kaston, I948).

Raising the forelegs and holding the abdomen to one side are by no means specific to courtship. This display occurs to a wide variety of objects that are approaching too close to the spider: other spiders - regardless of sex (Crane, I949), houseflies or other large prey, models of prey that are about the size of the spider, such as 9-12 mm spheres, or even the end of a finger or a pencil. In these situations, however, the spider with its forelegs raised and waving backs off while facing the moving object and, when $5-8 \mathrm{~cm}$ away, turns away and flees. In intraspecific encounters, the effect of raising the forelegs is to bring the other spider to an abrupt halt, whether it be a wandering cagemate, a courting male preparing to touch the female, or a female stalking or about to jump at the male. Indeed, raising of the forelegs appears to have this 'stop-sign' effect even in encounters between congenerics of the three Phidippus species. Drees, working with female Salticus scenicus, was able to initiate hunting behavior by moving a black dot along a white wall, and to stop the pursuing spider by moving wires projecting from the side of the model through an angle that imitated the waving of the forelegs (Drees, I952).

Female $P$. coccineus and $P$. apacheanus are unusual in that they perform an acceptance dance just before the male touches them. With forelegs high and wide apart and abdomen bent to the side, the female sways before the male, sometimes with a few steps to one side and then the other. In other Phidippus species, the female rejects the male by extending the first pair of legs whenever he approaches too closely, and merely fails to ward him off when she is ready to accept him.

Differences in the display of the three Phidippus species remain to be investigated. At this stage, it is apparent that subtle quantitative differences are involved. For example, while $P$. apacheanus moves his forelegs both closer and higher as he nears the female until the

Explanation of Plate 9

Figs. 13-16. Phidippus apacheanus Chamberlin and Gertsch. 13. Juvenile, total length $9 \mathrm{~mm}$. 14. Adult male below, female above, total length of each $11.5 \mathrm{~mm}$. Both male and females are black with bright orange dorsum of carapace and abdomen, and with iridescent green chelicerae. 15. Male signalling female. 16. Male signalling and facing female. 


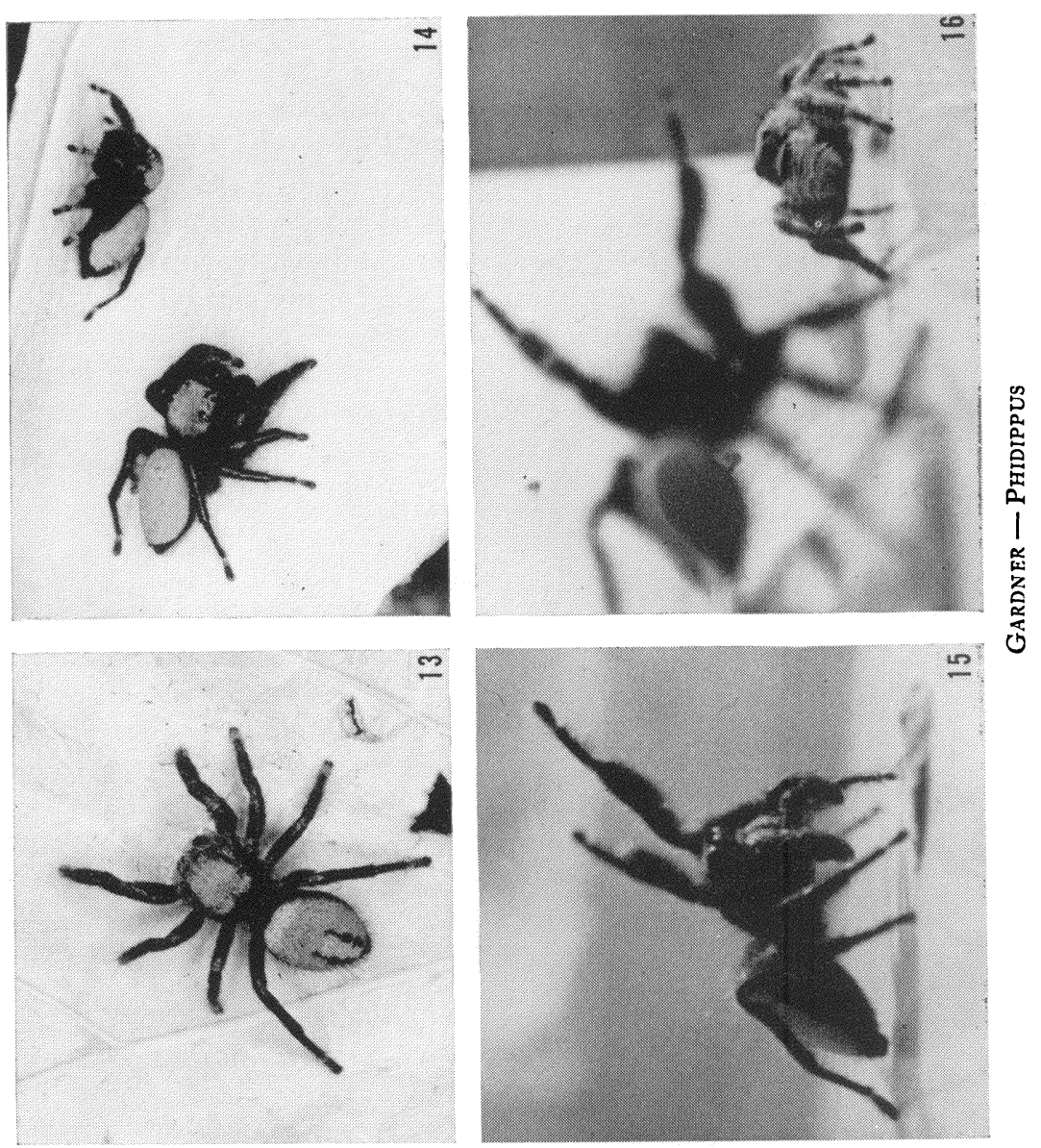


tips touch in a circle above his head, $P$. coccineus keeps his forelegs in the same vertical plane while bringing them together; again, $P$. apacheanus is only 5 to $8 \mathrm{~cm}$ away from the female when he begins to dance, and hence performs less extensive side-to-side movements than does $P$. coccineus (or $P$. clarus). There are also variations in the tempo of flicking the forelegs, and in the synchrony of the two forelegs, but further study is needed to sort out individual, drivelevel, and species differences.

As was previously noted, the adult apacheanus, coccineus, and opifex appear in the same habitat at different times, so that the time at which each species was courting did not overlap in the summer of 1964. However, adults of one species were kept in the laboratory until adults of the species succeeding them in the fields were collected. In the few relevant observations, the male courted the female of a different species as eagerly as his own (indeed, more eagerly if she were larger, as in the case of $P$. opifex females), while the female ran away or initiated hunting behavior as soon as she was released from the transparent vial.

\section{HUNTING}

\section{Method of observation}

Investigation of hunting behavior depends on techniques for controlling the hunger-level of the spider and the stimuli received from the prey.

As would be expected of a predator notorious for withstanding long fasts, the three Phidippus spp. will molt, reproduce, and survive many months in the laboratory, whether offered prey daily, bi-weekly, or once a week. To control hunger-level, a behavioral criterion for satiation was used: the spider was presented with successive Drosophila until it failed to accept a fly within Io min. of its presentation. Hunting was then tested at a specifiable level of food deprivation; tests at $\mathrm{I}, 7$, and $\mathrm{I} 2$ days deprivation yielded considerable variation in the intensity of hunting behavior (Gardner, 1964).

\section{Explanation of Plate 10}

Figs. 17-18. Phidippus coccineus Peckham and Peckham. 17. Juvenile, total length $5 \mathrm{~mm}$. The color is gray except for the abdomen. The abdomen dorsum has a white basal band and the reddish area is separated posterior by black bands broken by white spots. 18. Female, total length $10.5 \mathrm{~mm}$. Both males and females are black with bright red dorsum of the abdomen and iridescent blue-green chelicerae. The longitudinal black stripe on the abdomen is more distinct in females. The males (not illustrated) have a mean total length of $9 \mathrm{~mm}$. 

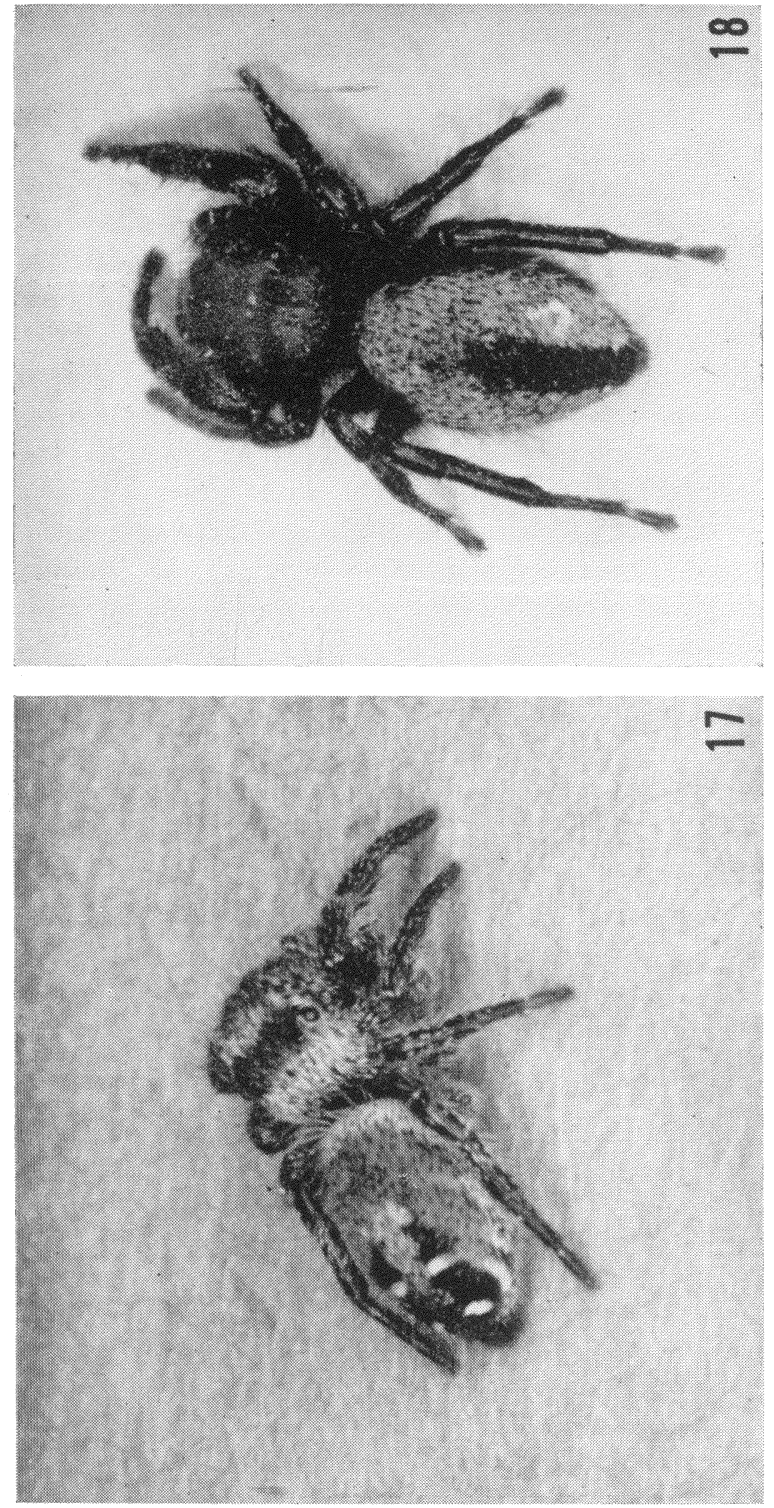
In hunting, as in courtship, visual stimuli are the most important, and complete hunting behavior can be observed with live prey in transparent containers, dead prey dangled by means of an attached fine gauge wire (or otherwise made to move), and simple models of prey, such as moving dots or spheres. In hunting, the spider is essentially tracking a moving target, and full control over the stimuli received from the prey is possible with a moving model whose speed, distance, and angular displacement can be regulated (Drees, 1952; Precht, 1952). The main difficulty in working with actual prey lies in the highly variable movements of living animals. To some extent, this can be overcome: flightless Drosophila mutants with a uniform manner of locomotion have obvious advantages over a prey that can fly, and hence sporadically disrupts an ongoing bout of hunting behavior by an abrupt change in angle and distance from the spider. It is important to arrange a situation in which the prey is not sometimes moving and sometimes still, as the spider seldom initiates hunting behavior to still prey, and interrupts ongoing hunting behavior when the prey ceases to move. Curly-type Drosophila melanogaster are suitable for this purpose as they crawl upward on a vertical surface and move continually until they have reached the top. The pathway of the prey in relation to the predator can also be made uniform. Jumping spiders will readily climb a slender pole, and position themselves, facing down, near the top; the curly-type Drosophila also climb such a pole, moving continually and at a constant speed straight toward the spider. With such a technique, the distance at which the spider initiates hunting can be measured, and can be compared for different species or for different periods of deprivation.

\section{Results}

Hunting behavior in salticid spiders can be described as a sequence of stimuli and responses: the spider performs a given response until there is some crucial change in the stimuli received from the prey which then evokes the succeeding response. Thus, when introduced into a hemispherical testing chamber, the spider generally climbs to the top. A few seconds after the prey enters, the spider orients by turning so that the large frontal eyes come in line with the prey, and this relative position is maintained throughout the remaining hunting responses. Once lined up, the spider pursues, moving rapidly at first but more slowly as it comes near the prey. When $P$. coccineus is within $5 \mathrm{~cm}$ of the prey, the spider presses its body close to the ground, and draws the legs in toward the body. At about $1.5 \mathrm{~cm}$, the spider becomes still in this crouched position, attaches a thread 
of silk to the substratum, and jumps at the prey. Somewhat more elaborate tracking occurs when a small $P$. coccineus pursues a much larger prey, such as a blue-bottle fly: the spider may take a curved course so that the final jump is from behind the prey.

It is possible to vary the frequency and duration of each hunting response by withholding the stimuli for the succeeding response (Drees, 1952; Precht, 1952; Gardner, 1964). For example, if the model is kept about $10 \mathrm{~cm}$ from the spider by moving it at the same speed as the pursuing predator, pursuit is prolonged far beyond its normal duration as the next response, crouching, requires a very small distance between prey and predator. Again, a model moving slowly within a transparent tube $2.5 \mathrm{~cm}$ in diameter seldom evokes jumping for the crouched spider cannot get close enough, while with a narrower tube jumping occurs readily.

Having captured the prey, the spider settles in one spot and does not move again until it has discarded the undigestible hard remains of the prey - a small mass in the case of the Drosophila, or the perfect empty shell of a large prey such as Calliphora. The time required to consume the prey reflects the relative size of the spider and its prey. For example, a group of small $(4-6 \mathrm{~mm})$ immature $P$. coccineus, tested at 7 days food deprivation, required a median time of $29.0 \mathrm{~min}$. to consume a Drosophila, while larger individuals (8-IO $\mathrm{mm}$ ) required only $8.6 \mathrm{~min}$. Even the large adult females required almost one hour to consume large prey such as Musca domestica. For P. coccineus (and P. clarus as well), consuming time increases reliably with days of food deprivation. Thus, the same group of small spiders required only $21.8 \mathrm{~min}$. to consume a Drosophila when tested at I day food deprivation.

Hungry $P$. coccineus will readily capture more than one prey at a time, provided the second prey comes very near (the spider will not move away from the place at which it has settled with the first prey). This situation was explored with the pole technique and perhaps it is common in the natural counterpart of the pole - the branch tips where hunting Phidippus can be found. The spiders accepted several pairs of prey on the pole, but as they became satiated, it was much less likely that they would accept the second prey. Instead, the spiders responded by extending the forelegs toward the Drosophila - once again using the ubiquitous display that occurs in courtship, intraspecific encounters, etc.

Given the choice between two prey that differ in size, such as Musca and Drosophila or Calliphora and Drosophila, P. coccineus chooses the large prey less consistently than does $P$. opifex and $P$. 
apacheanus. In the field, both opifex and apacheanus have been seen pursuing huge prey, such as grasshoppers and bees. A difference in preferred size of prey is also found between smaller and larger $P$. coccineus - although a $4 \mathrm{~mm}$ spiderling that pursued and caught a $9 \mathrm{~mm}$ housefly provides a notable exception. Both these factors would reduce competition for food among the three Phidippus species. At the present time, preferred size of prey is being investigated with models (spheres 3, 6, 9 and $\mathrm{I} 2 \mathrm{~mm}$ in diameter, moving at $8 \mathrm{~mm} / \mathrm{sec}$.).

\section{NeST BUILDING}

As Phidippus spends the daylight hours wandering from branch to branch while hunting prey, it seems likely that a new nest is built every evening. In their laboratory containers, $P$. coccineus only occasionally built more than one nest; ordinarily, the spiders returned to the same nest, night after night. If however, the nests are removed in the morning, the spiders will build a new nest late that afternoon. On a typical test day, 19 spiders had their nests removed and were exposed to natural light conditions. Of these, 16 built a nest within the next $24 \mathrm{hrs}$. All nest building began in the afternoon, at a median time of $55 \mathrm{~min}$. before sunset. (Such a generalization is limited to the sleeping nests of immature $P$. coccineus, for the molting nest is begun much earlier in the day, and the adult often lets many days pass without building.)

The spider begins to build by moving within a limited area in the angle formed between the sides and top of the container. As it moves, it attaches a framework of threads of silk, each about two or three times its own length. Suspended within these lines, the spider starts to weave by moving the abdomen from side to side so that the spinnerets describe an arc of a circle. Moving forward and back a step at a time, sometimes suspended on its back and sometimes on its venter, the spider spins about itself a closely woven tunnel, roughly one and one-half times its own length. Once started, weaving continues uninterrupted, and by $30 \mathrm{~min}$. after sunset most of the builders are quiet in their nests. The roles of light and temperature in the choice of nest-site and in the rather precise timing of this distinctive diurnal behavior are presently being investigated.

\section{Distribution of the SPECIES}

The male and female syntypes of $P$. coccineus came from Claremont, California and are kept in the Museum of Comparative Zoology. As far as known the species occurs in southern and eastern California and western Arizona. Phidippus opifex came from San 
Bernardino, California, the type should be in the Academy of Natural Sciences, Philadelphia but could not be found. Its distribution is in the southwestern United States. The male holotype of $P$. apacheanus came from Black Rock, Utah; it is common in the southwestern United States across the southern states to Kansas, Louisiana and possibly to the east coast.

\section{AcKNowledgements}

Dr. W. J. Gertsch provided the distribution data and identified $P$. opifex, Dr. Herbert W. Levi identified the other two species by comparing to the types and prepared the diagnostic illustrations. Jane E. Thompson, an NSF undergraduate research participant, made available her data on nest building. The photographs of $P$. apacheanus displaying are by Dr. G. P. Ginsburg; all other photographs are by Dr. Herbert W. Levi. The research was in part supported by Public Health Service Research Grants MH-07200 and MH-o8938 from the National Institute of Mental Health.

\section{References}

Chamberlin, R. V. and W. J. Gertsch

1929. New spiders from Utah and California, Pomona College, J. Entom. Zool., 21 : 101-112.

Crane, J.

1949. Analysis of display of Salticid spiders. Zoologica, New York, 34: 159-212.

DreEs, $O$.

1952. Untersuchungen über die angeborenen Verhaltensweisen bei

GARDNER, B. T. Springspinnen (Salticidae). Z. Tierpsychol., 9: 167-207.

1964. Hunger and sequential responses in the hunting behavior of Salticid spiders. J. Comp. Physiol. Psychol., 58: 164-173.

Kaston, B. J.

1948. Spiders of Connecticut. Hartford: State Geological and Natural History Survey, Bull. 70.

$\mathrm{McCook}, \mathrm{H}$. C.

1883. Proc. Acad. Nat. Sci., Philadelphia, p. 276.

Peckham, G. W. and E. G. Peckham

1909. Revision of the Attidae of North America. Trans. Wisconsin Precht, H. Acad. Sci. Arts Lett. 16: 355-646.

1952. Uber das angeborene Verhalten von Tieren. Versuche an Springspinnen (Salticidae). Z. Tierpsychol., 9: 207-230. 

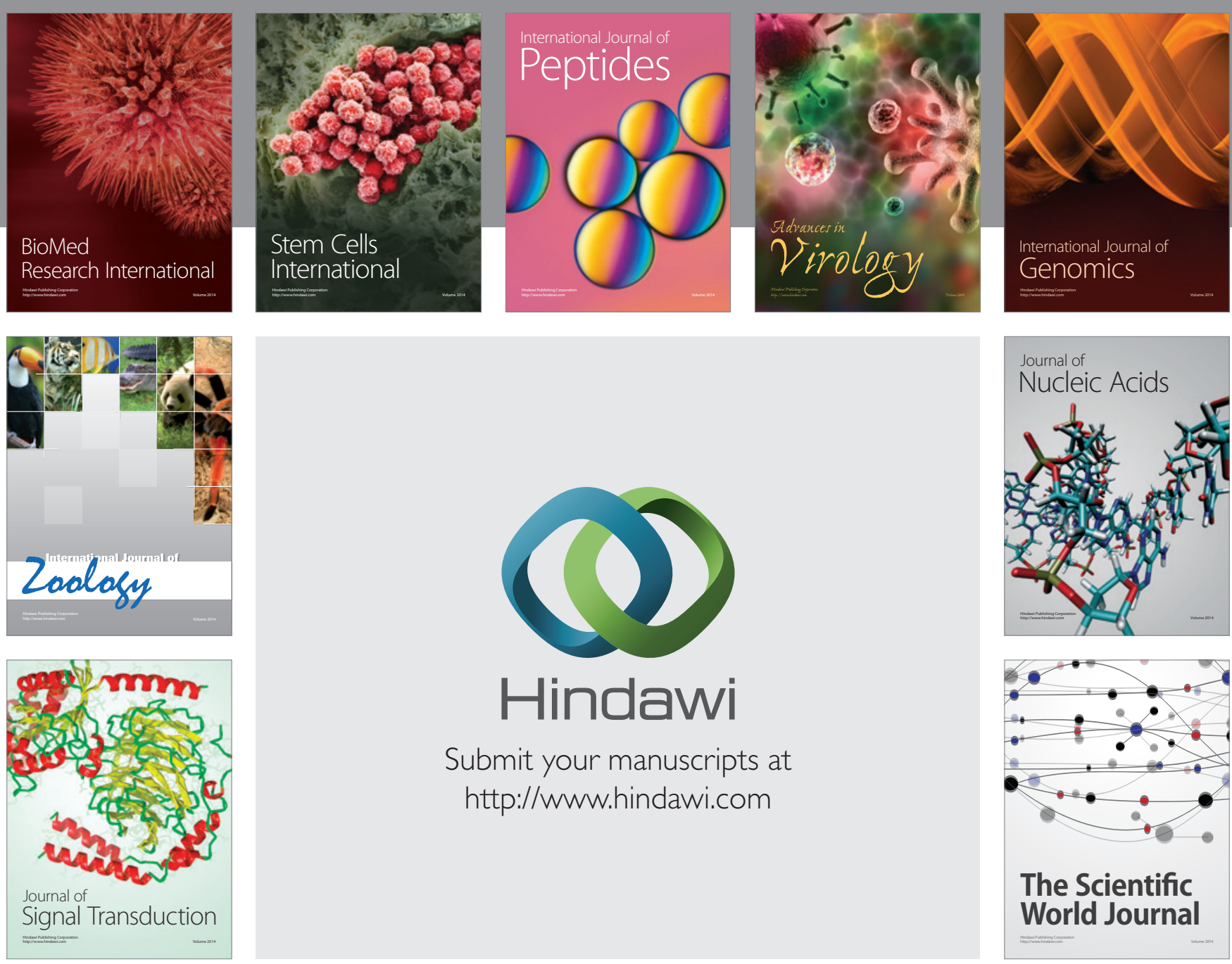

Submit your manuscripts at

http://www.hindawi.com
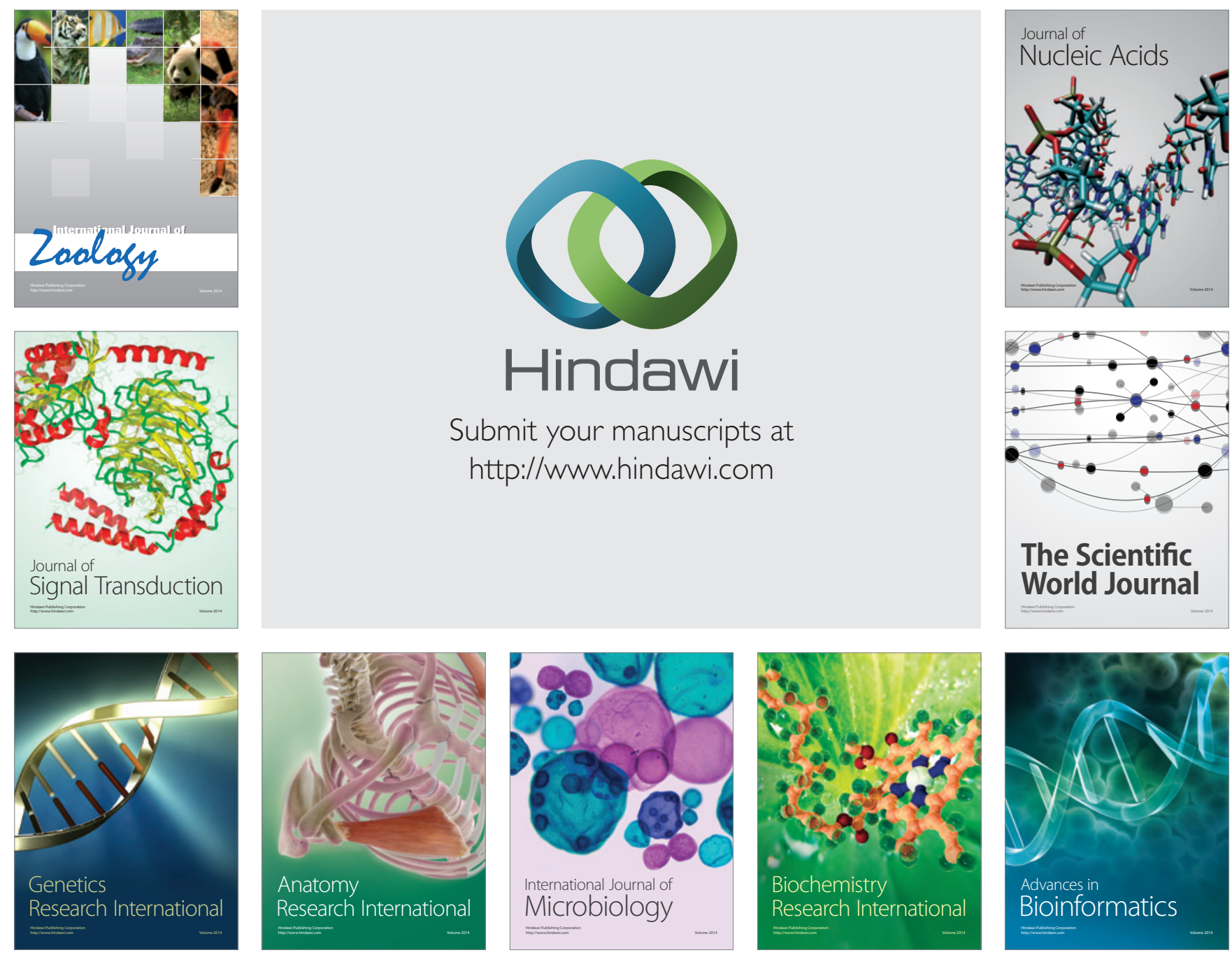

The Scientific World Journal
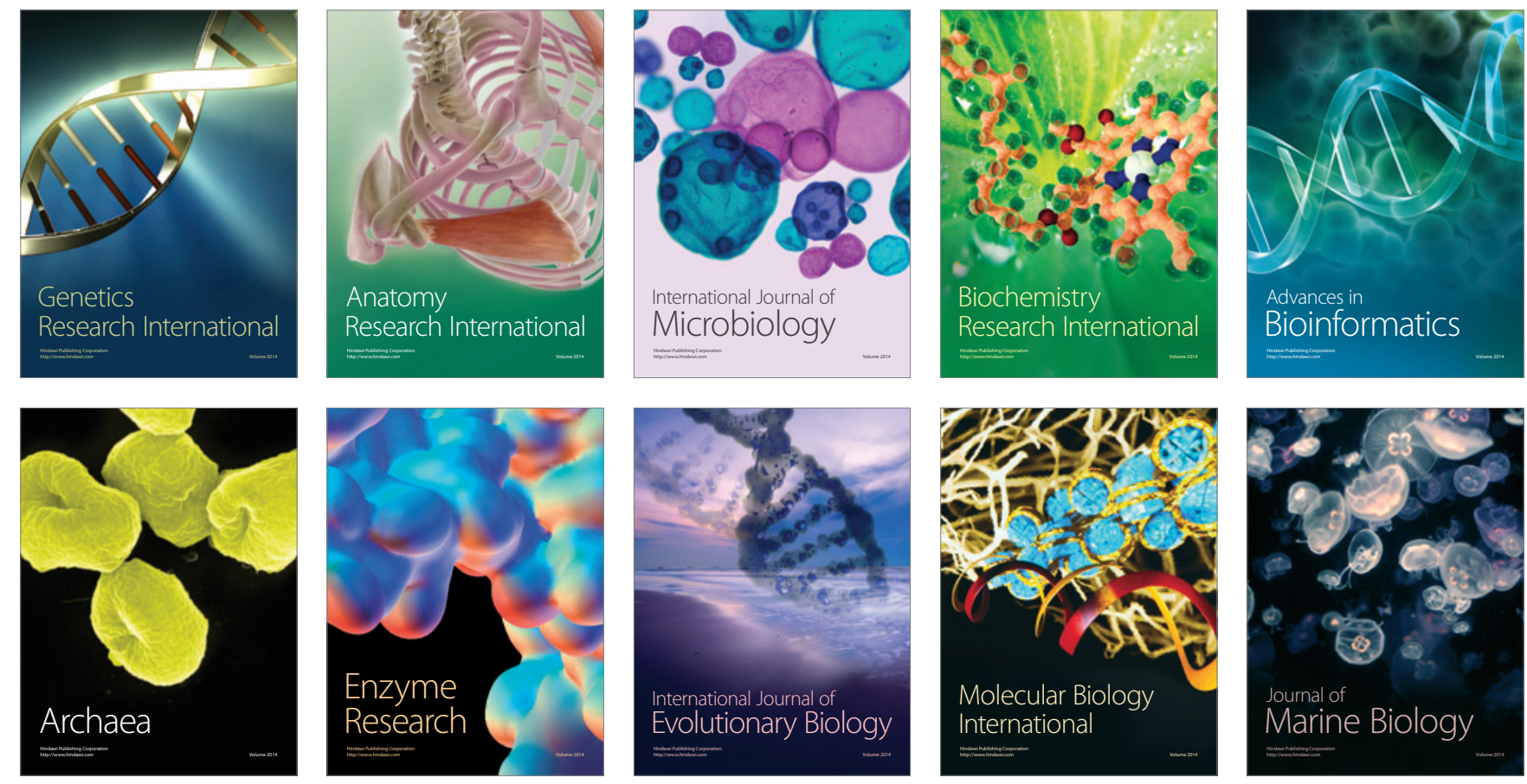